\title{
Dynamic Anthropometry- A Solution for Improving the Shape of Individual Protective Garments
}

\author{
Manuela Avadanei \\ Faculty of Industrial Design and Business Management \\ "Gheorghe Asachi" Technical University \\ Iasi, Romania
}

\begin{abstract}
Modern society has its values, which include justice, freedom, mutual respect, and responsibility. In this society, any human being has the right to be safe, to be respected, and they should, in turn, be empathetic and loyal to the other members of the society/community.

These values are valid not only for social life but also for the professional one. Thus, in any professional activity, the employee must be safe during their working time, because they have to fulfil specific tasks, which require different levels of effort. Among all types of professional jobs, there are several ones which require wearing a protective garment. This type of clothing is a component of the personal protective equipment, and it has to be designed according to some very well-defined safety and work standards. At the same time, the protective garment has to protect the employees from the dangerous action of the working actors and, to allow them to carry out the activities specific to the workplace.

Manufacturing individual protective garments are different from doing the same for fashion products because it has to take several additional factors into consideration, such as the work environment and the specific activities. Thus, the design process of the personal protective garments for activities that require physical effort is carried out by taking into account the amplitude of the movements and the areas of stress in the product. This paper presents the results of a dynamic anthropometry survey, which can be applied in designing patterns of individual protective garments. The study is focused on several specific human body dynamic positions (standardised positions of individual protective clothes). In this study, we considered several body positions, and we determined the values of the variables describing the dynamic effects in each situation. The trends of the aforementioned individual values were analysed by using statistical algorithms. These dynamic effects (absolute or relative values) can be used in the $2 D$ design scenario of the customised shapes of the patterns of the pieces from the structure of individual protective garments. With proper CAD tools, which allow a customised design process of the patterns and with adequate manufacturing technology, the employee will get a suitable individual protective garment for their job.
\end{abstract}

Keywords: Individual protective garments, dynamic anthropometry, dynamic effect, dimensional correspondence.

\section{INTRODUCTION}

Pattern design requires special skills and knowledge from different areas, such as the shape of the human body, properties of the materials, and visual design in order to understand, evaluate, and transpose all details from a garment sketch to a real product.
A designer must be aware of the importance of their work because their decisions at this stage influence the quality of the garment, which means that they have to determine and choose the optimal shape and structure for the components of the garment.

Fashionable garments are made by taking into account the current fashion trends (volume, materials, colours, lines, etc.) and customer requirements. These category of products are diverse, in a small number of items/model and are changing very often.

Individual protective garments have different requirements and follow different designing rules because first of all, they have to protect the wearer against the workplace risk factors. At the same time, these garments have to allow the worker to do their job safely and with minimal effort. $[1,3]$

Nowadays, fashionable items are usually customised because the designer interacts with the customer (face-to-face or in the virtual environment). However, for protective garments, the designer must follow a well-defined set of rules regarding garment sizes and materials. No matter if the clothing is designed in a 3D or $2 \mathrm{D}$ format, it still requires some information regarding human body measurements.

The anthropometric standards are taken from the known sources, and they provide information about standardised human bodies (the values of the body measurements) in static positions.[8]

These data are not enough in this case, because the designer has to dimension the garments for a moving. During motion, the position of the body is continuously changing, and consequently, the distances between different anthropometric points are altered as well. Thus, one should take an approach that takes into account the modification undergone by different body measurements for some positions of the trunk, head, and limbs that are very common during the individual's activities.

The difference between the value of a measurement taken for a certain dynamic position and the value of the same measurement recorded for a static position is called "dynamic effect". This parameter and can be expressed both in absolute values $(\mathrm{cm})$ and in percentages $(\%)[2,6]$.

It is very important to know the values of the dynamic effects, but their usage in the pattern construction process must be differentiated by taking into account the field in which the clothing is used (everyday clothing, working and protective clothing, sportswear). According to their type and use, the 
dynamic effects are either partially or totally considered in the design scenario of the garment patterns $[1,3]$.

The paper is focused on analysing the dynamic effects of some anthropometric dimensions, which were measured during different typical motions. These values of dynamic effects are recommended to be used for designing the patterns of overall protective garments, for the mechanical field, such as locksmiths, turners, milling-machine operators, welders, etc.: [9].

\section{WORK METHOD}

The observations on the working process in these fields of activity revealed a set of specific motions that are frequently performed. These motions especially stress the areas of the armhole-sleeve (the blouse) and the waist-crutch depth (trousers).

For this study, only four dynamic positions have been chosen to be analysed, because these are the most common ones. These motions also have an important influence on the distances between the anthropometric points, which means that they are causing important dynamic effects on the characteristics of the body.

In the first stage, a preliminary survey was carried out in order to decide upon the size of the sample. The end result is a 400 subjects sample, differentiated into age groups (see table 1), [7]

TABLE 1. The size of the sample

\begin{tabular}{|l|l|}
\hline Group of age (years old) & Number of subjects \\
\hline $20 \div 33$ & 209 \\
\hline $34 \div 45$ & 121 \\
\hline $45 \div 64$ & 70 \\
\hline
\end{tabular}

The body measurements were taken in a manually, according to the standard protocol [1,7]. The procedure consisted of the following steps:

1) The positions of the anthropometric points were marked on the surface of the human body. These points were used in order to obtain the needed anthropometric measurements, in both static and dynamic conditions;

2) The perimeters, lengths, body height, arcs and widths were measured in both static and dynamic conditions, while respecting the standard anthropometric survey procedure. Table 2 presents a list of these dimensions (codes, names and symbols).

TABLE 2 The list of the measured dimensions on the human body surface

\begin{tabular}{|l|l|l|}
\hline Code & The name of the body dimension & Symbol \\
\hline 0 & The body height & $\mathrm{Ic}$ \\
\hline 1 & The chest perimeter & $\mathrm{P}_{\mathrm{bII}}$ \\
\hline 2 & The bust perimeter & $\mathrm{P}_{\mathrm{bIII}}$ \\
\hline 3 & The waist perimeter & $\mathrm{P}_{\mathrm{t}}$ \\
\hline 4 & The front length from neck to waist & $\mathrm{L}_{\mathrm{Tf}}$ \\
\hline 5,14 & The back width & $\ell_{\mathrm{s}}$ \\
\hline 7 & The back arm length & $\mathrm{L}_{\mathrm{pbr}}$ \\
\hline 8 & The back length from armhole to wrist & $\mathrm{L}_{\mathrm{pms}}$ \\
\hline 9 & The top arm perimeter & $\mathrm{P}_{\mathrm{br}}$ \\
\hline 10 & The back armhole depth & $\mathrm{ARS}$ \\
\hline 11 & The nape to waist & $\mathrm{L}_{\mathrm{T}}$ \\
\hline 12 & The back length of the lower part of the trunk & $\mathrm{L}_{\mathrm{p} . \mathrm{tr}}$ \\
\hline 13 & The back transversal arch of the crutch region & $\mathrm{A}_{\mathrm{trf}}$ \\
\hline 15 & The oblique back arch & $\mathrm{I}_{\mathrm{ou}}$ \\
\hline
\end{tabular}

3) Four positions were considered for the dynamic study, labelled as follows: I, I, IV, and V (see table 3). For each human body position, a limited number of body measurements have been taken (see table 3), [8,10]

TABLE 3. Dynamic positions

\begin{tabular}{|l|l|}
\hline Code & $\begin{array}{l}\text { Position I } \\
\text { Deep breathing }\end{array}$ \\
\hline 5 &
\end{tabular}

\section{DETERMINING STATISTIC PARAMETERS OF THE MEASURED BODY DIMENSIONS}

The data of the survey have been statistically analysed by using the unidimensional analysis algorithm found in the Excel environment.

The selected body measurements were made in static and dynamic positions. For these dimensions, the following statistic parameters were determined:

-the average value $\rightarrow \bar{x}(\mathrm{~cm})$

-the selection variance $\rightarrow S_{x}^{2}\left(\mathrm{~cm}^{2}\right)$

-the standard deviation $\rightarrow S_{x}(\mathrm{~cm})$

-variation coefficient $\rightarrow V_{x}(\%)$

-the standard deviation of the average value $\rightarrow S_{\bar{x}}(\mathrm{~cm})$

-the limit error of the average value $\rightarrow \Delta \bar{x}(\mathrm{~cm})$

-the test of the average value $\rightarrow t_{\bar{x}}$ 
The significance of the sample is tested by calculating the $t_{\bar{x}}$ value and by comparing it with the tabulated values and quantiles of the Student test " $t$ " statistic [7].

The absolute $\left(\mathrm{d}_{\mathrm{ij}}\right)$ and relative $\left(\mathrm{e}_{\mathrm{dij}}\right)$ dynamic effects were calculated for each body measurement, on each subject (measured in static and in one or more dynamic positions) by using the following relations:

$$
\begin{aligned}
& \mathrm{d}_{\mathrm{ij}}=x_{i j}^{(d)}-x_{i j}^{(s)},(\mathrm{cm}) \\
& \mathrm{e}_{\mathrm{dij}}=\left(d_{i j} / x_{i j}^{(s)}\right) * 100(\%)
\end{aligned}
$$

\section{where:}

$x_{i j}^{(s)} \rightarrow$ the $\mathrm{i}^{\text {th }}$ body dimension measured on the $\mathrm{j}^{\text {th }}$ subject, in the static position;

$x_{i j}^{(d)} \rightarrow$ the $\mathrm{i}^{\text {th }}$ body dimension measured on the $\mathrm{j}^{\text {th }}$ subject, in a specific dynamic position (the same body dimension that had been measured in a static position).

Table 4 centralises the values of the main statistic parameters of the measured body dimensions for the whole sample (static and dynamic positions).

Table 5 shows the dynamic effects recorded in the selected dynamic positions.

Table 6 shows the level of the dynamic effects by taking into account the age group criterion.

Table 7 shows a comparison between the levels of dynamic effects obtained in our study and the ones from the literature.

By analysing the values of all statistic parameters, one draws important conclusions that are useful in designing the shape of the patterns of the individual protective garments.

\begin{tabular}{|c|c|c|c|c|c|c|c|c|}
\hline \multirow{2}{*}{$\begin{array}{l}\text { Cod } \\
\text { e }\end{array}$} & \multirow{2}{*}{$\begin{array}{l}\text { Body } \\
\text { positio } \\
\text { n }\end{array}$} & \multicolumn{7}{|c|}{ Values of statistics parameters (whole selection) } \\
\hline & & $\overline{\bar{x}}(\mathbf{c m})$ & $\begin{array}{l}S_{x}^{2} \\
\left(\mathbf{c m}^{2}\right)\end{array}$ & $\begin{array}{l}S_{x} \\
(\mathbf{c m})\end{array}$ & $\begin{array}{l}V_{x} \\
(\%)\end{array}$ & $\begin{array}{r}S_{\bar{x}} \\
(\mathbf{c m})\end{array}$ & $\begin{array}{l}\overline{\boldsymbol{x}} \\
(\mathbf{c m})\end{array}$ & $t_{\bar{x}}$ \\
\hline 0 & Static & 171,21 & 40 & 6.32 & 3.69 & 0.316 & 0.619 & 27.09 \\
\hline \multirow[t]{2}{*}{1} & Static & 99.68 & 77.43 & 8.8 & 8.83 & 0.44 & 0.862 & 11.33 \\
\hline & Pos.I & 102.03 & 56.30 & 7.5 & 7.35 & 0.375 & 0.735 & 13.60 \\
\hline \multirow[t]{2}{*}{2} & Static & 94.17 & 56.34 & 7.51 & 7.97 & 0.375 & 0.735 & 12.54 \\
\hline & Pos.I & 97.44 & 53.66 & 7.32 & 7.51 & 0.366 & 0.717 & 13.31 \\
\hline \multirow[t]{2}{*}{3} & Static & 84.69 & 113.8 & 10.67 & 11.89 & 0.534 & 1.046 & 7.94 \\
\hline & Pos. I & 84.79 & 100.4 & 10.02 & 11.81 & 0.501 & 0.981 & 8.46 \\
\hline \multirow[t]{2}{*}{4} & Static & 43.54 & 8.33 & 2.89 & 6.63 & 0.144 & 0.282 & 15.07 \\
\hline & Pos. I & 45.84 & 14.04 & 3.75 & 8.17 & 0.187 & 0.366 & 12.23 \\
\hline \multirow[t]{2}{*}{7} & Static & 23.56 & 3.43 & 1.85 & 7.86 & 0.092 & 0.180 & 12.74 \\
\hline & Pos. IV & 26.44 & 4.58 & 2.14 & 8.09 & 0.107 & 0.209 & 12.36 \\
\hline \multirow[t]{2}{*}{8} & Static & 48.49 & 6.82 & 2.61 & 5.39 & 0.131 & 0.256 & 18.58 \\
\hline & Pos. IV & 52.84 & 14.56 & 3.81 & 7.22 & 0.191 & 0.374 & 13.87 \\
\hline \multirow[t]{2}{*}{9} & Static & 29.95 & 10.11 & 3.18 & 10.62 & 0.159 & 0.312 & 9.42 \\
\hline & Pos. IV & 31.42 & 12.41 & 3.52 & 11.21 & 0.176 & 0.345 & 8.93 \\
\hline \multirow[t]{2}{*}{10} & Static & 17.77 & 4.62 & 2.15 & 12.09 & 0.107 & 0.209 & 8.23 \\
\hline & Pos. V & 19.03 & 3.13 & 2.26 & 11.90 & 0.113 & 0.221 & 8.42 \\
\hline \multirow[t]{2}{*}{11} & Static & 42.45 & 5.95 & 2.44 & 5.74 & 0.122 & 0.239 & 17.39 \\
\hline & Pos. V & 46.73 & 11.9 & 3.45 & 7.38 & 0.173 & 0.339 & 13.54 \\
\hline \multirow[t]{2}{*}{15} & Static & 46.69 & 8.79 & 2.97 & 6.35 & 0.148 & 0.290 & 15.72 \\
\hline & Pos. V & 54.09 & 12.24 & 3.49 & 6.40 & 0.175 & 0.343 & 15.50 \\
\hline \multirow[t]{2}{*}{12} & Static & 33.18 & 10.55 & 3.25 & 9.79 & 0.163 & 0.319 & 10.21 \\
\hline & Pos. V & 47.29 & 22.92 & 4.79 & 10.12 & 0.239 & 0.468 & 9.87 \\
\hline \multirow[t]{2}{*}{5} & Static & 39.95 & 10.24 & 3.2 & 8.01 & 0.16 & 0.314 & 12.48 \\
\hline & Pos. II & 52.12 & 16.01 & 4.00 & 7.68 & 0.20 & 0.392 & 13.03 \\
\hline
\end{tabular}

TABLE 4 The values of the main statistic parameters

\begin{tabular}{|l|l|l|l|l|l|l|l|l|}
\hline 14 & Pos. V & 54.32 & 18.07 & 4.25 & 7.82 & 0.212 & 0.416 & 12.78 \\
\hline \multirow{2}{*}{13} & Static & 49.49 & 20.63 & 4.54 & 9.18 & 0.227 & 0.445 & 10.90 \\
\cline { 2 - 9 } & Pos. V & 53.63 & 22.79 & 4.77 & 8.90 & 0.238 & 0.466 & 11.24 \\
\hline
\end{tabular}

TABLE 5 The dynamic effects recorded in several

\begin{tabular}{|c|c|c|c|c|c|c|c|c|c|}
\hline \multirow{3}{*}{$\begin{array}{l}\text { Dyn, } \\
\text { effect of } \\
\text { the body } \\
\text { dim. } x_{i} / \\
\text { position }\end{array}$} & \multirow{3}{*}{$\begin{array}{l}\text { Code } \\
x_{i}^{(d)} \\
x_{i}^{(s)}\end{array}$} & \multicolumn{8}{|c|}{ Statistic parameters } \\
\hline & & \multicolumn{2}{|c|}{$\overline{\bar{x}}$} & \multicolumn{2}{|c|}{$S_{x}$} & \multicolumn{2}{|c|}{$V_{x}$} & \multicolumn{2}{|c|}{$\Delta \bar{x}$} \\
\hline & & cm & $\%$ & cm & $\%$ & $\%$ & $\%$ & cm & $\%$ \\
\hline $\mathrm{P}_{\text {bII }} /$ pos.I & $1 / 1$ & 2.36 & 2.35 & 1.55 & 1.62 & 65.68 & 68.78 & 0.152 & 1.159 \\
\hline $\mathrm{P}_{\text {bIII }} /$ pos I & $2 / 2$ & 3.27 & 3.48 & 1.84 & 2.12 & 56.08 & 60.79 & 0.181 & 0.208 \\
\hline $\mathrm{P}_{\mathrm{t}} / \mathrm{pos} \mathrm{I}$ & $3 / 3$ & 1.66 & 1.92 & 1.38 & 1.61 & 83.57 & 84.20 & 0.136 & 0.158 \\
\hline $\mathrm{L}_{\mathrm{Tf}}^{\prime} / \operatorname{pos} \mathrm{I}$ & $4 / 4$ & 2.31 & 5.31 & 1.22 & 2.92 & 52.82 & 54.92 & 0.119 & 0.287 \\
\hline $\mathrm{L}_{\mathrm{pbr}} / \mathrm{pos} I V$ & $7 / 7$ & 2.88 & 12.41 & 1.27 & 5.87 & 44.18 & 47.29 & 0.125 & 0.577 \\
\hline $\mathrm{L}_{\mathrm{pms}} /$ posIV & $8 / 8$ & 4.35 & 8.97 & 2.49 & 5.29 & 57.23 & 58.93 & 0.244 & 0.519 \\
\hline $\mathrm{P}_{\mathrm{br}} / \operatorname{posIV}$ & $9 / 9$ & 1.48 & 4.95 & 0.91 & 3.08 & 61.69 & 62.20 & 0.089 & 0.302 \\
\hline ARS/posV & $10 / 10$ & 1.28 & 7.26 & 0.85 & 5.03 & 66.89 & 69.28 & 0.084 & 0.495 \\
\hline $\mathrm{L}_{\mathrm{T}} / \mathrm{pos} \mathrm{V}$ & $11 / 11$ & 4.31 & 10.12 & 1.81 & 4.28 & 42.06 & 42.28 & 0.018 & 0.421 \\
\hline $\mathrm{I}_{\mathrm{ou}} / \mathrm{pos} \mathrm{V}$ & $15 / 15$ & 8.02 & 17.25 & 2.56 & 5.84 & 31.98 & 33.88 & 0.252 & 0.574 \\
\hline $\mathrm{L}_{\text {p.itr }} / \mathrm{pos} \mathrm{V}$ & $12 / 12$ & 14.11 & 42.73 & 3.71 & 11.63 & 26.28 & 27.23 & 0.364 & 1.143 \\
\hline $\mathrm{A}_{\mathrm{trr}} / \operatorname{pos} \mathrm{V}$ & $13 / 13$ & 4.21 & 8.67 & 2.88 & 6.54 & 68.45 & 75.53 & 0.285 & 0.643 \\
\hline$\ell_{\mathrm{s}} / \operatorname{pos} \mathrm{V}$ & $5 / 5$ & 14.38 & 36.39 & 3.61 & 10.32 & 25.13 & 26.36 & 0.355 & 1.014 \\
\hline$\ell_{\mathrm{s}} /$ posII & $5 / 14$ & 12.16 & 30.46 & 3.06 & 8.60 & 25.11 & 27.97 & 0.300 & 0.875 \\
\hline
\end{tabular}
dynamic positions

TABLE 6 The dynamic effects calculated by taking into

\begin{tabular}{|c|c|c|c|c|}
\hline \multirow{2}{*}{$\begin{array}{l}\text { Body dim./ } \\
\text { Body position }\end{array}$} & \multicolumn{4}{|c|}{ Dynamic effects (\%) } \\
\hline & $\begin{array}{l}(20 \div 33) \\
\text { Years old }\end{array}$ & $\begin{array}{l}(34 \div 45) \\
\text { Years old }\end{array}$ & $\begin{array}{l}(46 \div 64) \\
\text { Years old }\end{array}$ & $\begin{array}{l}\text { Whole } \\
\text { selection }\end{array}$ \\
\hline Bust/pos I & 3.72 & 3.29 & 2.64 & 3.48 \\
\hline $\begin{array}{l}\text { Front length } \\
\text { from neck to } \\
\text { waist/ pos I }\end{array}$ & 5.59 & 5.41 & 4.41 & 5.31 \\
\hline $\begin{array}{l}\text { Nape to } \\
\text { waist/pos V }\end{array}$ & 11.27 & 9.19 & 7.10 & 10.12 \\
\hline $\begin{array}{l}\text { Back width/pos } \\
\text { V }\end{array}$ & 39.91 & 34.5 & 28.06 & 36.39 \\
\hline
\end{tabular}
account the age group criterion

TABLE 7 Dynamic effect- comparative data

\begin{tabular}{|l|l|l|}
\hline \multirow{2}{*}{$\begin{array}{l}\text { Body dimension/Body } \\
\text { position }\end{array}$} & \multicolumn{2}{|c|}{ Relative dynamic effect (\%) } \\
\cline { 2 - 3 } & $\begin{array}{l}\text { Data in the literature } \\
{[6]}\end{array}$ & $\begin{array}{l}\text { Data obtained in the } \\
\text { paper }\end{array}$ \\
\hline Waist/pos. I & 1.50 & 1.92 \\
\hline $\begin{array}{l}\text { Top arm perimeter/pos. } \\
\text { IV }\end{array}$ & 4.00 & 4.95 \\
\hline Back width/pos II & 36.90 & 36.39 \\
\hline $\begin{array}{l}\text { Back length of the } \\
\text { lower part of the } \\
\text { trunk/pos V }\end{array}$ & 45.60 & 42.73 \\
\hline $\begin{array}{l}\text { The oblique back } \\
\text { arch/pos V }\end{array}$ & 16.30 & 17.25 \\
\hline
\end{tabular}

\section{RESULTS INTERPRETATIONS AND CONCLUSIONS}

For all body measurements, measured both in static and in dynamic positions, the average values $(\bar{x})$ are significant from a statistical point of view because the $t_{\bar{x}}$ values are more significant than the p-value of the Student test, "t". (see table 4), [7].

The error of the average value $(\Delta x \overline{)}$ is below $0.5 \mathrm{~cm}$ (the standard measuring accuracy of the body measurements) so $(\bar{x})$ correctly estimates the average value of the population.

The values of $V_{x}$ are generally under $10 \%$, the particular values of the measured body dimensions are closer one to 
another, and closer to the average value as well (the biggest homogeneity degree).

The values of this statistics parameter, which are over $10 \%$, indicate a medium variability degree (medium homogeneity). These situations are recorded for the "waist perimeter" (11.89\% in the static scenario and $11.81 \%$ in the dynamic one), "top arm perimeter" $(10.62 \%$ in the static scenario and $11.21 \%$ in the dynamic one) and "back armhole depth" $(12.09 \%$ in the static scenario and $11.09 \%$ in the dynamic one). The values of these anthropometric dimensions are strongly influenced by the shape and posture of the human body, and they give us reasons to believe that different body shapes and postures used in the study were taken from a representative sample.

It is essential to mention that, the "back length of the lower part of the trunk" has a medium variability degree, slightly above $10 \%$, but only in the dynamic scenario.

The results from table 5 lead to the following conclusions:

-the values of $V_{x}$ indicate the biggest variability degree of individual values, as they are spread across a significant range, , with significant deviations from the average value as well.

-the absolute dynamic effect has the highest dispersion for "Pt/pos.I" (83,57\%) and the smallest one for " $\ell_{s} /$ pos.II" $(25,11 \%)$. The values of $V_{x}$ are influenced by the dynamic body position, by the subject's age and by their daily activities (depending on whether the person engages in activities involving physical effort or not).

-the average values of relative dynamic effects vary within a wide range. The smallest average values of relative effects were recorded for the "waist perimeter $\left(\mathrm{P}_{t} /\right.$ pos.I, 1.92), and the highest ones for "nape to waist" ( $\mathrm{L}$ p.itr/pos.V, 42.73). This is not surprising because in position $\mathrm{V}$ the body is exceedingly bent.

The error of the average values $(\Delta x \overline{)}$ of all dynamic effects are below $0.5 \mathrm{~cm}$ (the measuring accuracy of the body measurements) so $(\bar{x})$ is a good estimator for the average value of the population.

The dynamic effect depends on the measuring position of the body. For example, we obtained an average value of 14,38 $\mathrm{cm}$ in position $\mathrm{V}$ for the "back width" and $12.16 \mathrm{~cm}$ in position II for the same body measurement.

As expected, the values of the dynamic effects are influenced by the subject's age. Table 6 shows that, for the "young" range $20 \div 33$ (group I), the values of the dynamic effects are bigger than the ones obtained for the "old" range $46 \div 64$ years old (group III). The persons from the first group have higher mobility in joints and can develop more muscular force than the persons from the third one.

The results obtained in this study (dynamic effects) are comparable to the ones recorded in the literature (the same body positions and measurements), see the information from table 7[6].
In order to dimension the patterns of the overall products, the ease allowance values will be established by considering the values of the dynamic effects. The pattern of an overall product is obtained by combining the pattern of a blouse (straight silhouette) with one for trousers.

While designing the front pattern of the blouse, one has to determine the position of the bust line, waistline, and the level of the highest point. For this purpose, one has to take into account the dynamic effects registered for the following body measurements: ARS (position $\mathrm{V}$ ), $\mathrm{L}_{\mathrm{T}}$ (position $\mathrm{V}$ ), $\mathrm{L}_{\mathrm{Tf}}$ (position I). The modification of the back width in the position II will be considered in the transversal direction, in order to establish the back width of the blouse pattern.

In order to draft the trousers patterns, one has to take into account the modification of the waist perimeter during deep breathing (the position I). The back length of the lower part of the trunk and the back transversal arch of the crutch region will be taken into consideration in order to dimension the segments of the waist-crutch depth line.

Medical and anthropometric research shows that the secular trend characterises the evolution of humanity. In particular, the body shape of the young generation exhibits significant modifications, due to social, economic and social factors, lifestyle and education, than the previous one. It is reasonable to say that the shape and the dimensions of the human bodies will vary from a generation to another.

Under these circumstances, it is necessary to periodically update the information regarding the shape of the human body (values of anthropometric dimensions), for both static and dynamic positions. It is also essential to analyse the body posture, conformation and proportions because all these pieces of information are useful for designing and manufacturing customised products that fulfil all the customer's needs and requirements.

\section{REFERENCES}

[1] Brumariu, A., Mitu, S., Filipescu, E., Avădanei, M., etc.,-- Proiectarea constructivă a produselor de îmbrăcăminte, cap. VII.5, în Manualu inginerului textilist, vol. II, partea B, Lucrare editată de Ministerul Educatiei, Cercetării si Tineretului, Banca Comercială Română, 2003 , ISBN 973-8466-10-5, ISBN 973-8466-96-2, pag. 783-1044

[2] Jansen J."Systemschintt", vol. I, Berlin, 1994

[3] Kirakosian V.K. "Konstruirovanie mujskoi verhnei odejdî ispolizovaniem EVM", Legkaia i pişcevaia promîşlennosti, Moskova, 1982

[4] Nicolaiov, P., Florea, A., Loghin, C., Metode inovative de organizare a operaţiilor de lucru în sectorul confecţii textile (cap.1-6), Editura Certex, București, 2010, ISBN-978-973-1716-61-9

[5] Manolescu, A., Lefter, V., Deaconu, A., sa, Ergonomie, ed economica, Bucuresti, 2010, ISBN 978-973-709-491-9

[6] Suharev M.I., Boitova A.M., "Printzipi injenernovo proectirovania odejdy, Moscova, Legkaia i pishcevaia promyshlennosti, 1981

[7] Taloi D.,"Optimizarea proceselor metalurgice", Ed. didactică și pedagogică, Bucuresti, 1983.

[8] *** SR 13544. Îmbrăcăminte. Dimensiunile corpurilor și mărimi de confecţii pentru bărbaţi

[9] $* * *$ SR EN 13291/2007. Echipament individual de protective. Principii ergonomice

[10] *** STAS 5279-85. Imbracaminte. Masurarea corpului omenesc. 